\title{
Composição florística e estrutura de um fragmento de vegetação savânica sobre os tabuleiros pré-litorâneos na zona urbana de Fortaleza, Ceará ${ }^{1}$
}

\author{
Floristic composition and phytosociological structure of an urban savannic vegetation fragment \\ in the pre-litoranean plains of Fortaleza, Ceará
}

Marcelo Freire Moro ${ }^{1,3,4}$, Antônio Sérgio Farias Castro \& Francisca Soares de Araújo ${ }^{2}$

\begin{abstract}
Resumo
O crescimento urbano promove redução na cobertura vegetal, introdução de espécies exóticas e tem sérias implicações na conservação biológica. Um fragmento com vegetação savânica (24 ha - 347'55”S e 38²9'10”W) localizado na zona urbana de Fortaleza, Ceará, teve sua flora amostrada por coletas assistemáticas e teve um hectare inventariado em um estudo fitossociológico. Para a listagem florística foram coletadas espécies de todas as formas de crescimento presentes no fragmento. Para a descrição da estrutura da vegetação foram alocadas de forma aleatória oito transeções de 5' $250 \mathrm{~m}$ totalizando 1 ha, nas quais foram medidos os perímetros e altura dos indivíduos lenhosos com perímetro no nível do solo (PNS) maior ou igual a $9 \mathrm{~cm}$. Foram coletadas 151 espécies (138 indígenas e 13 exóticas) no levantamento florístico e 37 (35 indígenas) no levantamento fitossociológico. A densidade e a área basal total da comunidade foram, respectivamente, $1218 \mathrm{ind} / \mathrm{ha} \mathrm{e} 7,34 \mathrm{~m} / \mathrm{ha}$

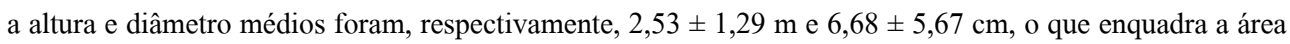
estudada dentro da amplitude de variações encontradas em áreas de cerrado sensu stricto e campo cerrado. Os resultados alcançados incrementam as poucas informações sobre as savanas costeiras do nordeste.
\end{abstract}

Palavras-chave: Cerrado, fitossociologia, florística, savanas pré-litorâneas, zona costeira.

\begin{abstract}
Urban growth promotes reduction in the vegetation cover, introduction of exotic species and has serious implications for biological conservation. In the urban area of Fortaleza, Ceará state, a vegetation fragment with savannic physiognomy ( 24 ha $-3^{\circ} 47^{\prime} 55^{\prime \prime}$ S and 38 $29^{\prime} 10^{\prime \prime} \mathrm{W}$ ) was sampled for a floristic survey and had 1 ha subjected to a phytosociological inventory. The floristic list of the fragment, considered a priority area for municipal conservation, is showed here. Phytosociological data have also been sampled, providing more information about the savannas from the Brazilian's Northeast coast. For the floristic list, species from all growth forms present in the fragment were collected. For the description of the structure of the vegetation, we assigned randomly eight transects with $5 \times 250 \mathrm{~m}$ (1 ha in total) in which the perimeters at ground level (PNS) and the total height of individual plants were measured for all woody plants with PNS greater than or equal to $9 \mathrm{~cm}$. In the floristic survey we collected 151 species (138 indigenous and 13 exotic) and in the phytosociological study, 37 species ( 35 native). The density and basal coverage of the community were $1218 \mathrm{ind} / \mathrm{ha}$ and $7.34 \mathrm{~m}^{2} / \mathrm{ha}$, respectively. The average height and average diameter were respectively $2.53 \pm 1.29 \mathrm{~m}$ and $6.68 \pm 5.67 \mathrm{~cm}$. Although our study site is geographically out of the Cerrado domain, it has structural variables compatible with the ones observed within the range of variations found in other Cerrado areas.
\end{abstract}

Key words: Cerrado, phytosociology, floristic, coastal savannas, coastal region.

${ }^{1}$ Parte da dissertação de Mestrado do primeiro autor, Programa de Pós-graduação em Desenvolvimento e Meio Ambiente (UFC).

${ }^{2}$ Universidade Federal do Ceará, Campus do Pici, Centro de Ciências, Depto. Biologia, 60455-760, bl. 906, Fortaleza, Ceará, Brasil

${ }^{3}$ Universidade Estadual de Campinas, Cidade Universitária “Zeferino Vaz”, Programa de Pós Graduação em Biologia Vegetal, Instituto de Biologia, CP 6109, 13083-970, Campinas, SP, Brasil.

${ }^{4}$ Autor para correspondência:bio_moro@yahoo.com.br 


\section{Introdução}

A conversão de áreas naturais para agricultura e crescimento urbano estão entre as principais causas de destruição e fragmentação de ecossistemas (UNDP, UNEP, WB, WRI 2000). Áreas urbanas já ocupam 471 milhões de hectares (em torno de $4 \%$ da superfície terrestre do planeta), o que torna necessário pensar a conservação biológica também em áreas dentro das cidades (UNDP, UNEP, WB, WRI 2000; McKinney 2002, 2006).

Dentre os principais riscos à conservação biológica nas cidades estão a eliminação da cobertura vegetal para expansão urbana e a introdução de espécies exóticas (McKinney 2002; Breuste 2004). Grandes cidades como Fortaleza detêm pouco da cobertura vegetal original (Fortaleza 2003) e mesmo fragmentos de vegetação remanescentes sofrem antropização em algum grau. O desmatamento de uma área para urbanização é a alteração ambiental mais drástica, mas a introdução de plantas exóticas também é um fator de preocupação, uma vez que plantas exóticas podem causar impactos negativos sobre a biodiversidade local (Richardson et al. 2000; McKinney 2002, 2006).

Conhecer a biodiversidade remanescente em fragmentos de vegetação de uma cidade é um passo importante para embasar políticas de conservação e justificar a criação de novas Unidades de Conservação. Dentre as fitofisionomias presentes na região costeira nordestina existem áreas que apresentam fisionomia savânica e uma flora onde a participação de espécies de Cerrado é notória. Essas áreas foram denominadas por Castro (1994) e Castro \& Martins (1999) de cerrados litorâneos e possuem uma flora composta por espécies do domínio do Cerrado, associadas a espécies de outros domínios (e.g. Oliveira-Filho \& Carvalho 1993). Um desses fragmentos costeiros de vegetação savânica foi mapeado no Inventário Ambiental de Fortaleza (Fortaleza 2003) e a área foi designada como prioritária para conservação pelo Plano Diretor da cidade (Município de Fortaleza 2009). A composição florística desses "cerrados costeiros", entretanto, é pouco conhecida e poucos levantamentos foram feitos nessas áreas (e.g. Oliveira-Filho \& Carvalho 1993).

O Cerrado, em seu sentido amplo, é composto por um conjunto de fisionomias xeromorfas submetidas a uma estação seca bem definida que ocupam, em sua área núcleo, o planalto central do Brasil (Eiten 1972; 1978). O cerrado sensu lato não se constitui em uma única vegetação, mas em um conjunto de diferentes fitofisionomias que variam desde vegetações campestres (campo limpo e campo sujo) até fisionomias florestais (cerradão). Em seu sentido restrito, o cerrado é uma savana, composta por um estrato contínuo e perene de espécies herbáceas que recobrem o solo, entremeadas por árvores e arbustos relativamente esparsos, que não constituem um dossel contínuo (Eiten 1972; Gottsberger \& Silberbauer-Gottsberger 2006; Ribeiro \& Walter 2008).

Embora a área núcleo (core area) do Cerrado esteja no Brasil central, ele se estende geograficamente até as Regiões Sul, Sudeste, Nordeste e Norte do Brasil, em áreas contíguas à área núcleo ou disjuntas dela (Eiten 1972; Ratter et al. 2003; Gottsberger \& Silberbauer-Gottsberger 2006). Manchas de vegetação savânica, denominadas por alguns autores de cerrados litorâneos, ocorrem de forma disjunta do domínio do cerrado sobre os tabuleiros pré-litorâneos da região costeira nordestina (Fernandes 1990; Oliveira-Filho \& Carvalho 1993; Figueiredo 1997; Castro 1994; Castro \& Martins 1999), mas a escassez de estudos florísticos e fitossociológicos dificulta a compreensão das suas relações florísticas com os grandes domínios fitogeográficos do Brasil.

Assim, o objetivo deste trabalho foi registrar a flora e descrever a estrutura de um fragmento de vegetação savânica localizado sobre os tabuleiros pré-litorâneos do Ceará, na zona urbana de Fortaleza, bem como avaliar o seu potencial para a conservação biológica no Município, propondo medidas para a conservação da área.

\section{Material e Métodos \\ Localização e caracterização geoambiental da área}

A cidade de Fortaleza, capital do estado do Ceará, situada na região costeira, localiza-se nas coordenadas 343'02'S e 38³2'35'W. O município tem uma área de $313,14 \mathrm{~km}^{2}$ e sua população é de 2.141.402 habitantes (IBGE 2000). Sua altitude média é de $16 \mathrm{~m}$, clima tropical quente subúmido, pluviosidade média anual de $1338 \mathrm{~mm}$ e temperatura média de 26 a $28^{\circ} \mathrm{C}$ (IPECE 2008). O município abrange terrenos da planície litorânea (dunas e paleodunas), dos tabuleiros pré-litorâneos (formação barreiras) e das planícies fluviais, sobre os quais ocorrem diferentes fitofisionomias (Fortaleza 2003; IPECE 2008; Figueiredo 1997). Fortaleza passou por um forte processo de urbanização ao longo do século XX e a cobertura vegetal da cidade atualmente é estimada em menos 
de $10 \%$ da original (Fortaleza 2003), de modo que as áreas ainda providas de vegetação estão restritas a fragmentos.

Para este estudo foi selecionado um fragmento de vegetação savânica de 24 hectares localizado na zona urbana de Fortaleza, Ceará. O fragmento em

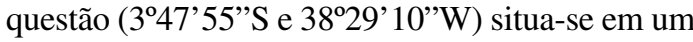
terreno de 28 hectares de propriedade da Empresa Brasileira de Correios e Telégrafos e do Exército brasileiro, no bairro Cambeba, e se encontra cercado de áreas já urbanizadas. Neste terreno há locais ocupados por residências, pomares de mangueiras (Mangifera indica) e até recentemente, parte do terreno era usado como área de treino de soldados do Exército (Fig. 1). No entorno das residências e em parte da área do exército há capinas para evitar o crescimento da vegetação. Estes trechos onde a vegetação é suprimida periodicamente pelas capinas foram chamadas de "áreas antropizadas" e, juntamente com áreas de pomar, somam cerca de 4 hectares, os quais foram excluídos da amostragem florística e fitossociológica (Fig. 1).

$\mathrm{O}$ fragmento, por estar localizado em uma matriz urbana, sofre diversas pressões e impactos. Os mais conspícuos são incêndios frequentes de origem antrópica; capinas no entorno das residências; deposito de lixo nas margens do fragmento, inclusive restos de plantas exóticas (e.g. Sansevieria spp e Opuntia dillenii (Ker Gawl.) Haw.) oriundas da manutenção de jardins, as quais poderiam se tornar naturalizadas ou invasoras no fragmento, a partir de reprodução vegetativa.

\section{Composição florística}

Para o levantamento florístico, coletas assistemáticas foram realizadas na vegetação ao longo do ano de 2008 e início de 2009. Todas as espécies encontradas foram coletadas segundo as técnicas usuais em botânica (Mori et al. 1985; Bridson \& Forman 1998) e depositadas no Herbário EAC, da Universidade Federal do Ceará.

A classificação das espécies em famílias seguiu aquela proposta pelo Angiosperm Phylogeny Group II (APG II 2003). Cada espécie foi classificada quanto à forma de crescimento baseada nas categorias propostas por Whittaker (1975), acrescidas das categorias subarbusto, hemi-parasita e parasita.

Espécies cultivadas como plantas ornamentais ou frutíferas no interior do terreno (e.g. Cocos nucifera L.; Hibiscus rosa-sinensis L.), mas que não haviam estabelecido populações reprodutivas na vegetação, foram excluídas da lista florística por não estarem integradas à flora do local. Espécies exóticas, para serem consideradas integradas à flora do fragmento e inseridas na lista florística, deveriam se enquadrar na definição de espécie invasora ou espécie naturalizada. Em relação à terminologia referente ao tema da bioinvasão, utilizaram-se as definições propostas por Richardson et al. (2000), em que: a) espécies exóticas: são espécies levadas pelo ser humano para uma área além do alcance natural da espécie; b) espécies naturalizadas: são espécies exóticas que se reproduzem e mantêm uma população auto perpetuante sem a intervenção humana direta na nova área onde foram introduzidas; c) espécies invasoras: são exóticas que, além de manter populações auto perpetuantes, conseguem se dispersar para locais afastados do ponto onde foram introduzidas pelo homem e, assim, invadir uma nova região.

\section{Estrutura fitossociológica}

Para o estudo fitossociológico, foi utilizada a metodologia de parcelas em transeções (belt transect) (Brower et al. 1997). Foram aleatoriamente alocadas oito transeções de $5 \times 250 \mathrm{~m}$ que totalizaram 1 ha, posicionadas na direção borda-interior do fragmento. Tomou-se o cuidado para que, no sorteio da posição de cada transeção, elas não caíssem sobre as áreas antropizadas ou os pomares de mangueiras e para que o eixo longitudinal de cada transeção estivesse a pelo menos $100 \mathrm{~m}$ de distância da matriz urbana (Fig. 1), evitando que a transeção se posicionasse inteiramente na margem do fragmento. Cada transeção foi dividida sequencialmente em subparcelas de $5 \times 10 \mathrm{~m}$ (total de 200 subparcelas amostradas nas oito transeções). Em cada subparcela foram medidos o perímetro no nível do solo (PNS) e a altura de todos os indivíduos lenhosos, exceto trepadeiras, com PNS mínimo de $9 \mathrm{~cm}$. Uma exsicata de cada espécie foi depositada no herbário EAC.

A partir da altura e perímetro de cada indivíduo, associados à identificação taxonômica, foram calculados os parâmetros tradicionais de estrutura da vegetação (Durigan 2003): densidade (absoluta e relativa); área basal (absoluta e relativa) e frequência (absoluta e relativa). Também foram calculados a altura e o diâmetro médios da comunidade, bem como o índice de diversidade de Shannon. Para determinar o peso de cada espécie na comunidade usou-se o Índice de Valor de Importância (IVI) que corresponde à soma da Densidade Relativa, Frequência Relativa e Área Basal Relativa de todos os indivíduos da mesma espécie (Brower et al. 1997; McCune \& Grace 2002; Durigan 2003). 


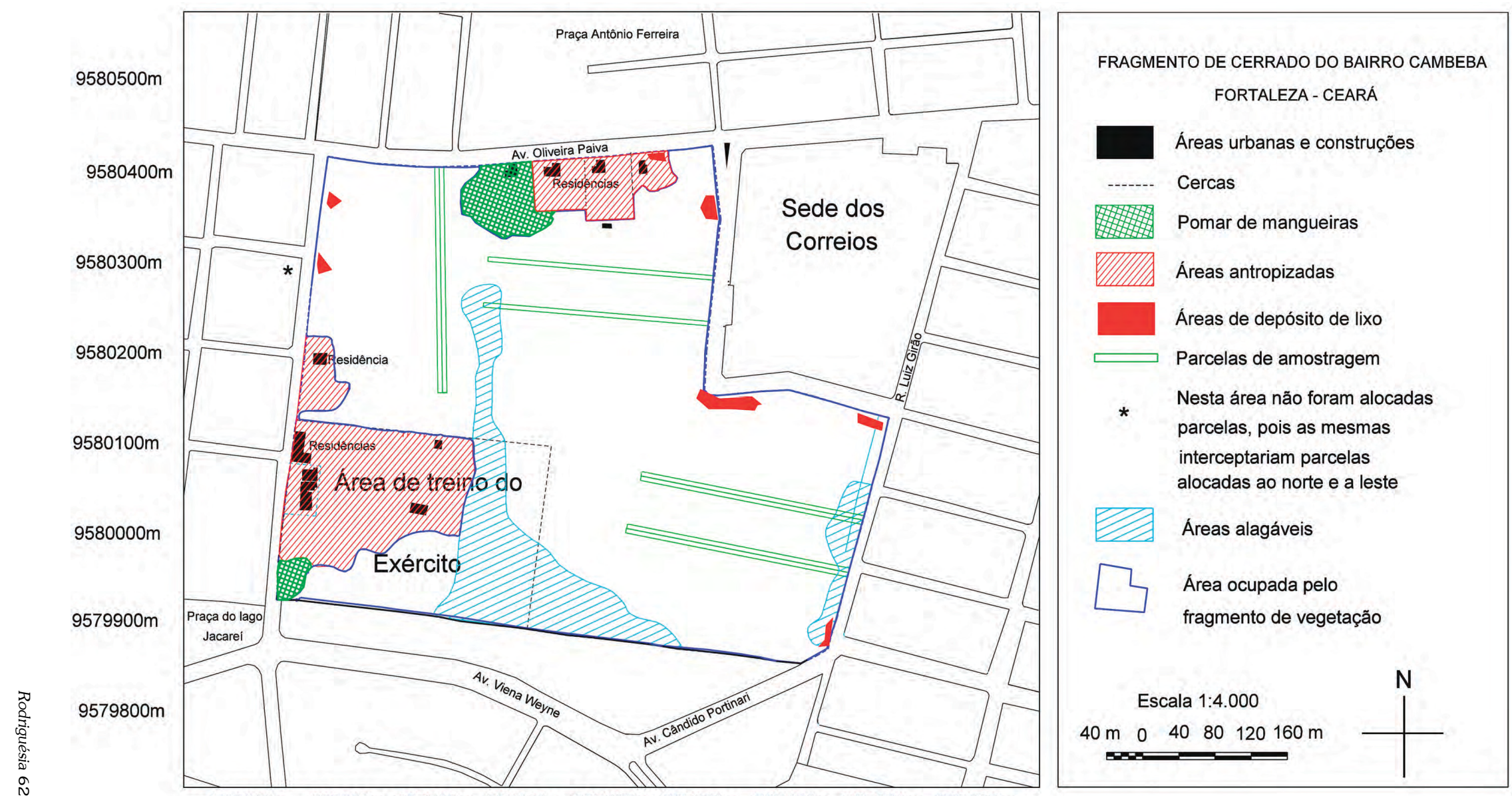

556800m 556900m 557000m 557100m 557200m 557300m 557400m 557500m 557600m

Figura 1 - Mapa do terreno onde se localiza o fragmento de vegetação savânica estudado, sobre os tabuleiros pré-litorâneos de Fortaleza, Ceará, 2008. Coordenadas UTM: zona 24M. (Elaboração: M. F. Moro)

Figure 1 - Map of the savannic vegetation fragment studied on the pre-litoranean plains of Fortaleza, Ceará state, 2008. UTM coordinates: Zone 24M. 


\section{Resultados}

\section{Composição florística}

Foram registradas 151 espécies vegetais pertencentes a 61 famílias (Tab. 1). Fabaceae foi a família com maior riqueza (28 espécies - uma exótica), seguida de Poaceae (nove espécies - três exóticas), Rubiaceae (oito espécies), Convolvulaceae (sete espécies), Malvaceae (sete espécies) e Myrtaceae (seis espécies - uma exótica), as quais juntas representam $43 \%$ da riqueza de espécies registrada na área. As espécies exóticas representam treze espécies ( $8,6 \%$ da flora local) e Poaceae foi a família com a maior riqueza de exóticas, com três espécies.

Quanto à forma de crescimento, as ervas foram representadas por 57 espécies (38\%), os arbustos totalizaram 35 espécies (23\%), as árvores 33 (22\%), as trepadeiras $20(13 \%)$, além de três espécies subarbustivas, duas hemiparasitas e uma parasita.

Tabela 1 - Lista das espécies, hábitos e números do coletor (M.F. Moro) das plantas coletadas no fragmento de vegetação savânica sobre os tabuleiros pré-litorâneos de Fortaleza, Ceará, 2008. * Espécie exótica invasora sensu Richardson et al. (2000); ** Espécie exótica naturalizada sensu Richardson et al. (2000)

Table 1 - Species list, habits, and collector numbers (M.F. Moro) of the plants collected in the the savannic vegetation fragment studied on the pre-litoranean plain. Fortaleza, Ceará state, 2008. *Invasive plant sensu Richardson et al. (2000); **Naturalized plant sensu Richardson et al. (2000).

\begin{tabular}{|c|c|c|c|}
\hline Família/Espécies & Nome popular & Hábito & $\mathbf{N}^{\circ}$ col \\
\hline \multicolumn{4}{|l|}{ ACANTHACEAE } \\
\hline Ruellia sp. & & erva & 632 \\
\hline $\begin{array}{l}\text { AMARANTHACEAE } \\
\text { Alternanthera brasiliana }(\mathrm{L} .) \text { Kuntze }\end{array}$ & quebra-panela & erva & 554 \\
\hline \multicolumn{4}{|l|}{ ANACARDIACEAE } \\
\hline Anacardium occidentale L. & cajueiro & árvore & 607 \\
\hline Mangifera indica $\mathrm{L} . * *$ & mangueira & árvore & 647 \\
\hline Tapirira guianensis Aubl. & pau-pombo & árvore & 649 \\
\hline \multicolumn{4}{|l|}{ ANNONACEAE } \\
\hline \multicolumn{4}{|l|}{ APOCYNACEAE } \\
\hline Calotropis procera (Aiton) W.T. Aiton* & hortência; ciúme & arbusto & 617 \\
\hline Himatanthus drasticus (Mart.) Plumel & janaguba & árvore & 512 \\
\hline Tabernaemontana catharinensis A. DC. & grão-de-galo & arbusto & 579 \\
\hline \multicolumn{4}{|l|}{ ARECACEAE } \\
\hline Acrocomia intumescens Drude & macaúba & árvore & 662 \\
\hline Copernicia prunifera (Mill.) H.E. Moore & carnaúba & árvore & 654 \\
\hline \multicolumn{4}{|l|}{ ASTERACEAE } \\
\hline Conyza bonariensis (L.) Cronquist & & erva & 521 \\
\hline Elephantopus hirtiflorus DC. & língua-de-vaca & erva & 527 \\
\hline Porophyllum ruderale (Jacq.) Cass. & & erva & 678 \\
\hline Wedelia sp. & camará & erva & 667 \\
\hline \multicolumn{4}{|l|}{ BIGNONIACEAE } \\
\hline Benth. \& Hook. f. ex S. Moore & caraúba & árvore & 630 \\
\hline \multicolumn{4}{|l|}{ BIXACEAE } \\
\hline \multicolumn{4}{|l|}{ BORAGINACEAE } \\
\hline Heliotropium polyphyllum Lehm. & & erva & 659 \\
\hline Tournefortia candidula (Miers) I.M. Johnst. & & trepadeira & 608 \\
\hline \multicolumn{4}{|l|}{ CANNABACEAE } \\
\hline Trema micrantha (L.) Blume & periquiteira & árvore & 571 \\
\hline
\end{tabular}




\begin{tabular}{|c|c|c|c|}
\hline Família/Espécies & Nome popular & Hábito & $\mathbf{N}^{\mathbf{o}}$ col \\
\hline \multicolumn{4}{|l|}{ CELASTRACEAE } \\
\hline Maytenus erythroxyla Reissek & casca-grossa & arbusto & 587 \\
\hline \multicolumn{4}{|l|}{ CHRYSOBALANACEAE } \\
\hline Hirtella ciliata Mart. \& Zucc. & açoita-cavalo & arbusto & 655 \\
\hline Hirtella racemosa Lam. & & arbusto & 556 \\
\hline Licania rigida Benth. & oiticica & árvore & 616 \\
\hline \multicolumn{4}{|l|}{ COMMELINACEAE } \\
\hline Commelina benghalensis L. * & & erva & 524 \\
\hline \multicolumn{4}{|l|}{ CONVOLVULACEAE } \\
\hline Ipomoea asarifolia (Desr.) Roem. \& Schult. & salsa & erva & 592 \\
\hline Ipomoea bahiensis Willd. ex Roem. \& Schult. & & trepadeira & 673 \\
\hline Ipomoea quamoclit $\mathrm{L}$. & & trepadeira & 520 \\
\hline Ipomoea sp. & & trepadeira & 650,562 \\
\hline Jacquemontia serrata Meisn. & & trepadeira & 513 \\
\hline Jacquemontia tamnifolia (L.) Griseb. & & trepadeira & 677 \\
\hline Merremia aegyptia (L.) Urb. & jitirana & trepadeira & 591 \\
\hline \multicolumn{4}{|l|}{ CUCURBITACEAE } \\
\hline Momordica charantia L.* & melão-de-são-caetano & trepadeira & 666 \\
\hline \multicolumn{4}{|l|}{ CYPERACEAE } \\
\hline Bulbostylis cf. junciformis (Kunth) C.B.Clarke & & erva & 640 \\
\hline Cyperus ligularis L. & capim-açu & erva & 657 \\
\hline Cyperaceae sp1 & & erva & 519 \\
\hline \multicolumn{4}{|l|}{ DILLENIACEAE } \\
\hline Curatella americana $\mathrm{L}$. & cajueiro-bravo & árvore & 542 \\
\hline Davilla cearensis Huber & cipó-de-fogo & trepadeira & 574 \\
\hline \multicolumn{4}{|l|}{ EBENACEAE } \\
\hline Diospyros cf. inconstans Jacq. & fruta-de-cabra & arbusto & 661 \\
\hline \multicolumn{4}{|l|}{ ERIOCAULACEAE } \\
\hline Paepalanthus sp. & & erva & 685 \\
\hline \multicolumn{4}{|l|}{ ERYTHROXYLACEAE } \\
\hline Erythroxylum suberosum var. denudatum O.E. Schulz & & arbusto & 614 \\
\hline \multicolumn{4}{|l|}{ EUPHORBIACEAE } \\
\hline Cnidoscolus urens (L.) Arthur & cansansão & arbusto & 611 \\
\hline Croton blanchetianus Baill. & marmeleiro & arbusto & 643 \\
\hline Dalechampia pernambucensis Baill. & cipó-urtiga & trepadeira & 590 \\
\hline Euphorbia hyssopifolia L. & erva-de-leite & erva & 583 \\
\hline Ricinus communis L.* & mamona, carrapateira & arbusto & 558 \\
\hline \multicolumn{4}{|l|}{ FABACEAE - CAESALPINIOIDEAE } \\
\hline Chamaecrista diphylla (L.) Greene & erva-de-coração & erva & 593 \\
\hline Chamaecrista hispidula (Vahl) H.S. Irwin \& Barneby & & erva & 601 \\
\hline Hymenaea courbaril $\mathrm{L}$. & jatobá & árvore & 674 \\
\hline Senna rizzinii H.S. Irwin \& Barneby & & arbusto & 573 \\
\hline \multicolumn{4}{|l|}{ FABACEAE - FABOIDEAE } \\
\hline Abrus precatorius L.* & jiriquiti & trepadeira & 668 \\
\hline Acosmium dasycarpum (Vogel) Yakovlev & pau-paratudo & árvore & 563 \\
\hline Aeschynomene marginata Benth. & & erva & 561 \\
\hline Andira surinamensis (Bondt) Splitg.ex Pulle & angelim & árvore & 588 \\
\hline Centrosema brasilianum (L.) Benth. & & trepadeira & 597 \\
\hline Chamaecrista flexuosa (L.) Greene & & erva & 511 \\
\hline Clitoria laurifolia Poir. & & erva & 570 \\
\hline Crotalaria stipularia Desv. & & erva & 596 \\
\hline Desmodium barbatum (L.) Benth. & & erva & 682 \\
\hline
\end{tabular}




\begin{tabular}{|c|c|c|c|}
\hline Família/Espécies & Nome popular & Hábito & $\mathrm{N}^{\circ} \mathrm{col}$ \\
\hline Desmodium distortum (Aubl.) J.F.Macbr. & rapadura-de-cavalo & Subarbusto & 559 \\
\hline Dioclea lasiophylla Mart. ex Benth. & & trepadeira & 530 \\
\hline Indigofera hirsuta L.* & anileira & erva & 582 \\
\hline Macroptilium gracile (Poepp. ex Benth.)Urb. & feijão-de-rola & trepadeira & 595 \\
\hline Macroptilium lathyroides (L.) Urb. & feijão-de-rola & erva & 651 \\
\hline Rhynchosia phaseoloides (Sw.) DC. & & trepadeira & 628 \\
\hline Stylosanthes angustifolia Vogel & & erva & 604 \\
\hline Stylosanthes guianensis var. gracilis (Kunth) Vogel & & erva & 560 \\
\hline Zornia tenuifolia Moric. & & erva & 599 \\
\hline \multicolumn{4}{|l|}{ FABACEAE - MIMOSOIDEAE } \\
\hline Albizia lebbeck (L.) Benth. * & esponjinha, albízia & árvore & 645 \\
\hline Enterolobium timbouva Mart. & timbaúba & árvore & 613 \\
\hline Mimosa camporum Benth. & malícia & arbusto & 546 \\
\hline Mimosa somnians Humb. \& Bonpl. ex Willd. & malícia & arbusto & 529 \\
\hline Samanea tubulosa (Benth.) Barneby \& J.W. Grimes & bordão-de-velho & árvore & 664 \\
\hline Stryphnodendron coriaceum Benth. & barbartimão & árvore & 549 \\
\hline \multicolumn{4}{|l|}{ GENTIANACEAE } \\
\hline Schultesia guianensis (Aubl.) Malme & & erva & 598 \\
\hline \multicolumn{4}{|l|}{ HYDROLEACEAE } \\
\hline Hydrolea spinosa $\mathrm{L}$. & espinho-de-judeu & Subarbusto & 534 \\
\hline \multicolumn{4}{|l|}{ HYPERICACEAE } \\
\hline Vismia guianensis (Aubl.) Pers. & & arbusto & 606 \\
\hline \multicolumn{4}{|l|}{ IRIDACEAE } \\
\hline Cipura xanthomelas Mart. ex Klatt & & erva & 548,555 \\
\hline \multicolumn{4}{|l|}{ LAMIACEAE } \\
\hline Aegiphila lhotskiana Cham. & & árvore & 639 \\
\hline Amasonia campestris (Aubl.) Moldenke & erva & 545 & \\
\hline Hypenia salzmannii (Benth.) Harley & canela-de-ema & erva & 610 \\
\hline Vitex polygama Cham. & & árvore & 689 \\
\hline \multicolumn{4}{|l|}{ LAURACEAE } \\
\hline Cassytha filiformis $\mathrm{L}$. & cipó-chumbo & Parasita & 633 \\
\hline \multicolumn{4}{|l|}{ LENTIBULARIACEAE } \\
\hline Utricularia sp. & & erva & 688 \\
\hline \multicolumn{4}{|l|}{ LORANTHACEAE } \\
\hline Struthanthus sp. & erva-de-garapeiro & hemiparasita & 642 \\
\hline \multicolumn{4}{|l|}{ MALPIGHIACEAE } \\
\hline Byrsonima crassifolia $($ L.) Kunth & murici & arbusto & 626,516 \\
\hline Byrsonima sericea $\mathrm{DC}$. & murici & árvore & 557,658 \\
\hline \multicolumn{4}{|l|}{ MALVACEAE } \\
\hline Guazuma ulmifolia Lam. & mutamba & árvore & 638 \\
\hline Melochia sp. & malva & erva & 568 \\
\hline Pavonia cancellata (L.) Cav. & & trepadeira & 553 \\
\hline Peltaea trinervis (C. Presl) Krapov. \& Cristóbal & & arbusto & 531 \\
\hline Sida linifolia Cav. & & arbusto & 680 \\
\hline Sterculia striata A. St.-Hil. \& Naudin & xixá & árvore & 644,631 \\
\hline Waltheria indica $\mathrm{L}$. & malva & arbusto & 538 \\
\hline \multicolumn{4}{|l|}{ MELASTOMATACEAE } \\
\hline Mouriri cearensis Huber & manipuçá & arbusto & 623 \\
\hline Pterolepis glomerata (Rottb.) Miq. & & erva & 566 \\
\hline \multicolumn{4}{|l|}{ MORACEAE } \\
\hline Ficus elliotiana S. Moore & gameleira & árvore & 636 \\
\hline
\end{tabular}




\begin{tabular}{|c|c|c|c|}
\hline Família/Espécies & Nome popular & Hábito & $\mathbf{N}^{0}$ col \\
\hline \multicolumn{4}{|l|}{ MYRTACEAE } \\
\hline Campomanesia aromatica (Aubl.) Griseb. & guabiraba & arbusto & 663 \\
\hline Eugenia punicifolia (Kunth) DC. & murta & arbusto & $515,537,540$ \\
\hline Myrcia splendens (Sw.) DC. & goipuna & árvore & 618 \\
\hline Myrcia tomentosa (Aubl.) DC. & & arbusto & 634 \\
\hline Myrciaria cuspidata O. Berg & & arbusto & 641 \\
\hline Syzygium cumini (L.) Skeels * & azeitona-roxa & árvore & 646 \\
\hline \multicolumn{4}{|l|}{ OCHNACEAE } \\
\hline Ouratea hexasperma (A. St.-Hil.) Baill. & batiputá & arbusto & 514 \\
\hline Sauvagesia erecta $\mathrm{L}$. & & erva & 565 \\
\hline \multicolumn{4}{|l|}{ OLACACEAE } \\
\hline Ximenia americana $\mathrm{L}$. & ameixa & arbusto & 669 \\
\hline \multicolumn{4}{|l|}{ OPILIACEAE } \\
\hline Agonandra brasiliensis Miers ex Benth. \& Hook. f. & pau-marfim & árvore & 625 \\
\hline \multicolumn{4}{|l|}{ ORCHIDACEAE } \\
\hline Cyrtopodium holstii L.C. Menezes & rabo-de-tatu & erva & 671 \\
\hline Habenaria allemanii Barb. Rodr. & & erva & 535,602 \\
\hline Oeceoclades maculata (Lindl.) Lindl. * & & erva & 629 \\
\hline \multicolumn{4}{|l|}{ OROBANCHACEAE } \\
\hline Agalinis hispidula (Mart.) D’Arcy & & erva & 686 \\
\hline \multicolumn{4}{|l|}{ PASSIFLORACEAE } \\
\hline Passiflora cincinnata Mast. & maracujá-do-mato & trepadeira & 635 \\
\hline Passiflora foetida $\mathrm{L}$. & maracujá-do-mato & trepadeira & 541 \\
\hline \multicolumn{4}{|l|}{ PHYTOLACCACEAE } \\
\hline Rivina humilis L. & & erva & 536 \\
\hline \multicolumn{4}{|l|}{ PLANTAGINACEAE } \\
\hline Achetaria sp. & & arbusto & 683 \\
\hline Tetraulacium veroniciforme Turcz. & & erva & 567 \\
\hline \multicolumn{4}{|l|}{ PLUMBAGINACEAE } \\
\hline Plumbago scandens L. & pega-pinto & trepadeira & 586 \\
\hline \multicolumn{4}{|l|}{ POACEAE } \\
\hline Andropogon bicornis L. & & erva & 533 \\
\hline Andropogon selloanus (Hack.) Hack. & & erva & 532 \\
\hline Gymnopogon foliosus (Willd.) Nees & & erva & 676 \\
\hline Hyparrhenia rufa (Nees) Stapf * & capim-jaraguá & erva & 580 \\
\hline Megathyrsus maximus (Jacq.) B.K. Simon \& S.W.L. Jacobs* & capim-colonião & erva & 517 \\
\hline Panicum trichoides Sw. & & erva & 585 \\
\hline Paspalum maritimum Trin. & capim-gengibre & erva & 518 \\
\hline Pennisetum pedicellatum Trin. * & & erva & 584 \\
\hline Trachypogon spicatus (L. f.) Kuntze & & erva & 522 \\
\hline \multicolumn{4}{|l|}{ POLYGALACEAE } \\
\hline Polygala sp. & & erva & 528 \\
\hline Polygala martiana A.W. Benn. & & erva & 603 \\
\hline \multicolumn{4}{|l|}{ POLYGONACEAE } \\
\hline Coccoloba latifolia Lam. & coaçu & arbusto & 572 \\
\hline \multicolumn{4}{|l|}{ RUBIACEAE } \\
\hline Diodella apiculata (Willd. ex Roem. \& Schult.) Delprete & & erva & 564 \\
\hline Diodella gardneri (K.Schum.) Bacigalupo \& E.L.Cabral & & erva & 575 \\
\hline Genipa americana $\mathrm{L}$. & jenipapo & árvore & 652 \\
\hline Guettarda angelica Mart. ex Müll. Arg. & angélica & arbusto & 609 \\
\hline Ixora sp. & & arbusto & 612,615 \\
\hline
\end{tabular}




\begin{tabular}{|c|c|c|c|}
\hline Família/Espécies & Nome popular & Hábito & $\mathbf{N}^{\circ}$ col \\
\hline Mitracarpus salzmannianus DC. & & Subarbusto & 576 \\
\hline Spermacoce verticillata $\mathrm{L}$. & & erva & 569 \\
\hline Tocoyena sellowiana (Cham. \& Schltdl.) K. Schum. & jenipapo-bravo & arbusto & 665 \\
\hline RUTACEAE & & & \\
\hline Zanthoxylum rhoifolium Lam. & limãozinho & árvore & 675 \\
\hline SALICACEAE & & & \\
\hline Casearia sylvestris $\mathrm{Sw}$. & & arbusto & 656 \\
\hline $\begin{array}{l}\text { SANTALACEAE } \\
\text { Phoradendron affine (Pohl ex DC.) Engl. \& K. Krause }\end{array}$ & erva-de-passarinho & hemiparasita & 627 \\
\hline SAPINDACEAE & & & \\
\hline Talisia esculenta (A. St.-Hil.) Radlk. & pitombeira & árvore & 670 \\
\hline SAPOTACEAE & & & \\
\hline Chrysophyllum arenarium Allemão & mamão-de-bode & arbusto & 577 \\
\hline SIMAROUBACEAE & & & \\
\hline Simaba trichilioides A. St.-Hil. & pra-tudo & arbusto & 578 \\
\hline Simarouba versicolor A. St.-Hil. & pau-paraíba & árvore & 551 \\
\hline SMILACACEAE & & & \\
\hline Smilax cissoides Mart. ex Griseb. & japicanga & trepadeira & 589 \\
\hline SOLANACEAE & & & \\
\hline Solanum paludosum Moric. & & arbusto & 550 \\
\hline Solanum paniculatum $\mathrm{L}$. & jurubeba & arbusto & 594 \\
\hline TURNERACEAE & & & \\
\hline Turnera subulata $\mathrm{Sm}$. & chanana & erva & 552 \\
\hline URTICACEAE & & & \\
\hline Cecropia pachystachya Trécul & torém & árvore & 637 \\
\hline VERBENACEAE & & & \\
\hline Stachytarpheta sessilis Moldenke & pescoço-de-ganso & erva & 523 \\
\hline VIOLACEAE & & & \\
\hline Hybanthus calceolaria (L.) Oken & ipepaconha & erva & 653 \\
\hline
\end{tabular}

\section{Estrutura fitossociológica}

Foram amostrados 1218 indivíduos lenhosos vivos e 379 indivíduos mortos em pé. Dentre os vivos, foram registradas 37 espécies lenhosas pertencentes a 24 famílias na amostragem fitossociológica (Tab. 2). Das 37 espécies amostradas, duas, Syzygium cumini e Albizia lebbeck, são exóticas, mas têm pequena importância sociológica na área estudada. A densidade e a área basal total da comunidade foram, respectivamente, $1218 \mathrm{ind} / \mathrm{ha} \mathrm{e} 7,34 \mathrm{~m}^{2} / \mathrm{ha}$.

Quanto à altura, 64\% dos indivíduos vivos amostrados possuíram altura inferior a $3 \mathrm{~m}$ (Fig. 2), enquanto a altura média foi de $2,53 \pm 1,29 \mathrm{~m}$. O porte da vegetação foi baixo, embora haja trechos com árvores que atingem 6-7 m (árvores de até $9 \mathrm{~m}$ foram registradas), os quais contrastam com trechos do fragmento praticamente sem árvores, onde a comunidade herbácea predomina (Fig. 3 a-d, 4 a).
Em relação à estrutura horizontal da comunidade $64 \%$ dos indivíduos tiveram diâmetro menor do que $6 \mathrm{~cm}$ (Fig. 5). O diâmetro médio foi de $6,68 \pm 5,67 \mathrm{~cm}$. O valor do índice de diversidade de Shannon (H') foi de 2,64 nat/indivíduos.

\section{Discussão}

\section{Composição florística}

A flora lenhosa nativa do fragmento estudado é constituída por uma mistura de espécies típicas da área núcleo do Cerrado com outras espécies da zona costeira do Nordeste, mas que não ocorrem no Planalto Central. Espécies como Anacardium occidentale, Acosmium dasycarpum, Tapirira guianensis, Simarouba versicolor, Annona coriacea e Erythroxylum suberosum, registradas neste estudo, são espécies frequentes em outras áreas de Cerrado do Brasil e foram registradas em 
Tabela 2 - Parâmetros fitossociológicos registrados em 1 ha do fragmento de vegetação savânica estudado, em ordem decrescente de Índice de Valor de Importância (IVI) das espécies lenhosas. Fortaleza, Ceará, 2008. Ocorrência: Cas - Espécie presente em outras áreas de cerrado do Brasil, segundo Castro et al. (1999); Rat - Espécie presente em outras áreas de cerrado do Brasil, segundo Ratter et al. (2003); CE - Espécie presente em outras áreas de cerrado do Ceará, segundo Costa et al. (2004); Costa \& Araújo (2007) e Figueiredo \& Fernandes (1987).

Table 2 - Phytosociological parameters in 1 ha of the savannic vegetation fragment studied, in decreasing order of Importance Value Index (IVI) of the woody species. Fortaleza, Ceará state, 2008. .Geographical distribution: Cas - Species recorded in other Cerrado areas of Brazil according to Castro et al. (1999); Rat - Species recorded in other Cerrado areas of Brazil according to Ratter et al. (2003); CE - Species recorded in other Cerrado areas in Ceará state according to Costa et al. (2004); Costa \& Araújo (2007) and Figueiredo \& Fernandes (1987).

\begin{tabular}{|c|c|c|c|c|c|c|c|c|c|}
\hline \multirow[t]{2}{*}{ Espécie } & \multicolumn{2}{|c|}{ Densidade } & \multicolumn{2}{|c|}{ Área Basal } & \multicolumn{3}{|c|}{ Frequência } & \multirow{2}{*}{$\begin{array}{l}\mathbf{N}^{\mathbf{0}} \text { coletor } \\
\text { (M.F. Moro) }\end{array}$} & \multirow[t]{2}{*}{ Ocorrência } \\
\hline & $\begin{array}{l}\text { Absoluta } \\
\text { (ind/ha) }\end{array}$ & $\begin{array}{l}\text { Relativa } \\
(\%)\end{array}$ & $\begin{array}{l}\text { Absoluta } \\
\left(\mathrm{cm}^{2} / \mathrm{ha}\right)\end{array}$ & $\begin{array}{c}\text { Relativa } \\
(\%)\end{array}$ & $\begin{array}{l}\text { Absoluta } \\
(\%)\end{array}$ & $\begin{array}{l}\text { Relativa } \\
(\%)\end{array}$ & I.V.I. & & \\
\hline Himatanthus drasticus (Mart.) Plumel & 329 & 27,01 & 11628,98 & 15,83 & 48,50 & 21,75 & 64,59 & 512 & $\mathrm{CE}$ \\
\hline Stryphnodendron coriaceum Benth. & 166 & 13,63 & 17759,31 & 24,18 & 32,00 & 14,35 & 52,16 & 549 & Cas, Rat, CE \\
\hline Ouratea hexasperma (A. St.-Hil.) Baill. & 150 & 12,32 & 8648,35 & 11,77 & 21,50 & 9,64 & 33,73 & 514 & Cas, Rat \\
\hline Annona coriacea Mart. & 73 & 5,99 & 2541,25 & 3,46 & 19,50 & 8,74 & 18,20 & 624 & Rat, CE \\
\hline Anacardium occidentale L. & 17 & 1,40 & 10394,48 & 14,15 & 5,00 & 2,24 & 17,79 & 607 & Cas, Rat, CE \\
\hline Simarouba versicolor A.St.-Hil. & 62 & 5,09 & 3020,61 & 4,11 & 11,50 & 5,16 & 14,36 & 551 & Cas Rat CE \\
\hline Byrsonima crassifolia (L.) Kunth & 39 & 3,20 & 2935,44 & 4,00 & 15,00 & 6,73 & 13,93 & 626 & Rat, CE \\
\hline $\begin{array}{l}\text { Tabebuia aurea (Silva Manso) Benth. \& Hook. } \\
\text { f. ex S. Moore }\end{array}$ & 32 & 2,63 & 2124,88 & 2,89 & 8,00 & 3,59 & 9,11 & 630 & Cas, Rat, CE \\
\hline Agonandra brasiliensis Miers ex Benth. \& Hook. f. & 52 & 4,27 & 1809,63 & 2,46 & 4,00 & 1,79 & 8,53 & 625 & Cas, Rat, CE \\
\hline Tapirira guianensis Aubl. & 38 & 3,12 & 1360,54 & 1,85 & 7,50 & 3,36 & 8,34 & 649 & Cas, Rat \\
\hline Acosmium dasycarpum (Vogel) Yakovlev & 27 & 2,22 & 1352,23 & 1,84 & 5,00 & 2,24 & 6,30 & 563 & Rat \\
\hline Tabernaemontana catharinensis A. DC. & 40 & 3,28 & 518,29 & 0,71 & 4,50 & 2,02 & 6,01 & 579 & Cas \\
\hline Coccoloba latifolia Lam. & 32 & 2,63 & 377,24 & 0,51 & 5,50 & 2,47 & 5,61 & 572 & \\
\hline Guettarda angelica Mart. ex Müll. Arg. & 29 & 2,38 & 481,70 & 0,66 & 4,50 & 2,02 & 5,05 & 609 & Cas \\
\hline Curatella americana $\mathrm{L}$. & 6 & 0,49 & 2232,01 & 3,04 & 2,00 & 0,90 & 4,43 & 542 & Cas, Rat, CE \\
\hline Byrsonima sericea DC. & 10 & 0,82 & 1125,89 & 1,53 & 3,50 & 1,57 & 3,92 & 557 & Cas, Rat, CE \\
\hline
\end{tabular}




\begin{tabular}{|c|c|c|c|c|c|c|c|c|c|}
\hline \multirow[t]{2}{*}{ Espécie } & \multicolumn{2}{|c|}{ Densidade } & \multicolumn{2}{|c|}{ Área Basal } & \multicolumn{3}{|c|}{ Frequência } & \multirow{2}{*}{$\begin{array}{l}\mathbf{N}^{\mathbf{o}} \text { coletor } \\
\text { (M.F. Moro) }\end{array}$} & \multirow[t]{2}{*}{ Ocorrência } \\
\hline & $\begin{array}{l}\text { Absoluta } \\
\text { (ind/ha) }\end{array}$ & $\begin{array}{c}\text { Relativa } \\
(\%)\end{array}$ & $\begin{array}{l}\text { Absoluta } \\
\left(\mathrm{cm}^{2} / \mathrm{ha}\right)\end{array}$ & $\begin{array}{c}\text { Relativa } \\
(\%)\end{array}$ & $\begin{array}{c}\text { Absoluta } \\
(\%)\end{array}$ & $\begin{array}{c}\text { Relativa } \\
(\%)\end{array}$ & I.V.I. & & \\
\hline Sterculia striata A.St.-Hil. \& Naudin & 15 & 1,23 & 1119,68 & 1,52 & 2,50 & 1,12 & 3,88 & 644 & Cas, Rat \\
\hline Mouriri cearensis Huber & 10 & 0,82 & 958,67 & 1,31 & 2,50 & 1,12 & 3,25 & 623 & \\
\hline Campomanesia aromatica (Aubl.) Griseb. & 19 & 1,56 & 322,89 & 0,44 & 2,00 & 0,90 & 2,90 & 663 & \\
\hline Cochlospermum vitifolium (Willd.) Spreng. & 8 & 0,66 & 199,14 & 0,27 & 3,50 & 1,57 & 2,50 & 605 & Cas, Rat \\
\hline Croton blanchetianus Baill. & 17 & 1,40 & 207,16 & 0,28 & 0,50 & 0,22 & 1,90 & 643 & \\
\hline Guazuma ulmifolia Lam. & 2 & 0,16 & 1021,22 & 1,39 & 0,50 & 0,22 & 1,78 & 638 & Cas, Rat \\
\hline Myrcia splendens (Sw.) DC. & 5 & 0,41 & 210,96 & 0,29 & 2,00 & 0,90 & 1,59 & 618 & Rat \\
\hline Aegiphila lhotskiana Cham. & 6 & 0,49 & 112,20 & 0,15 & 1,50 & 0,67 & 1,32 & 639 & Cas, Rat \\
\hline Hirtella ciliata Mart. \& Zucc. & 3 & 0,25 & 287,14 & 0,39 & 1,50 & 0,67 & 1,31 & 655 & Cas, Rat, CE \\
\hline Casearia sylvestris $\mathrm{Sw}$. & 6 & 0,49 & 86,90 & 0,12 & 1,50 & 0,67 & 1,28 & 656 & Cas, Rat \\
\hline Ixora sp. & 5 & 0,41 & 54,93 & 0,07 & 1,00 & 0,45 & 0,93 & 615 & \\
\hline Albizia lebbeck (L.) Benth. & 3 & 0,25 & 204,85 & 0,28 & 0,50 & 0,22 & 0,75 & 645 & \\
\hline Eugenia punicifolia (Kunth) DC. & 3 & 0,25 & 25,54 & 0,03 & 1,00 & 0,45 & 0,73 & 537 & Cas, Rat, CE \\
\hline Chrysophyllum arenarium Allemão & 3 & 0,25 & 22,52 & 0,03 & 1,00 & 0,45 & 0,73 & 577 & Rat, CE \\
\hline Simaba trichilioides A.St.-Hil. & 2 & 0,16 & 14,40 & 0,02 & 1,00 & 0,45 & 0,63 & 578 & \\
\hline Myrcia tomentosa (Aubl.) DC. & 3 & 0,25 & 71,06 & 0,10 & 0,50 & 0,22 & 0,57 & 634 & Cas, Rat \\
\hline Myrciaria cuspidata O. Berg & 2 & 0,16 & 51,73 & 0,07 & 0,50 & 0,22 & 0,46 & 641 & \\
\hline Cecropia pachystachya Trécul & 1 & 0,08 & 76,47 & 0,10 & 0,50 & 0,22 & 0,41 & 637 & Cas, Rat \\
\hline Syzygium cumini (L.) Skeels & 1 & 0,08 & 74,03 & 0,10 & 0,50 & 0,22 & 0,41 & 646 & \\
\hline Tocoyena sellowiana (Cham. \& Schltdl.) K. Schum. & 1 & 0,08 & 7,96 & 0,01 & 0,50 & 0,22 & 0,32 & 665 & \\
\hline Solanum paludosum Moric. & 1 & 0,08 & 6,45 & 0,01 & 0,50 & 0,22 & 0,32 & 550 & \\
\hline TOTAIS & 1.218 & 100,00 & $73.446,72$ & 100,00 & 223,00 & 100,00 & 300,00 & - & \\
\hline
\end{tabular}




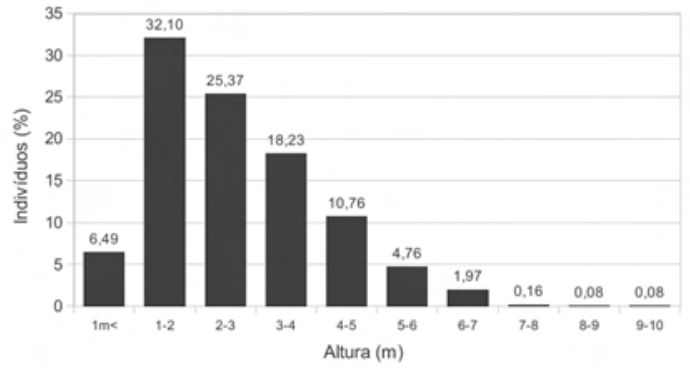

Figura 2 - Classes de altura dos indivíduos lenhosos em 1 ha no fragmento de vegetação savânica estudado. Fortaleza, Ceará, 2008.

Figure 2 - Height classes of the woody plants sampled in 1 ha of the savannic vegetation fragment studied. Fortaleza, Ceará state, 2008

mais de 100 locais de coleta por Ratter et al. (2003). Várias outras espécies, também presentes no Cerrado (e.g. Genipa americana, Sterculia striata, Eugenia punicifolia, Cochlospermun vitifolium e Stryphnodendron coriaceum) foram registradas na flora da área estudada.

Espécies lenhosas comuns na região costeira do Nordeste, mas que não ocorrem em cerrados da área núcleo (segundo as compilações feitas por Castro et al. 1999 e Ratter et al. 2003), como Coccoloba latifolia, Mouriri cearensis, Maytenus erythroxyla, Campomanesia aromatica e Tocoyena sellowiana, se misturam nesta mancha de cerrado sobre os tabuleiros pré-litorâneos com as espécies típicas dos cerrados centrais para compor a flora da área estudada. Isso justifica o fato de os cerrados costeiros terem formado um subgrupo com identidade florística distinta nas análises realizadas por Castro (1994) e Castro \& Martins (1999). Segundo Castro (1994), a diferenciação florística dos cerrados pré-litorâneos se manteve não apenas quando comparados aos cerrados do planalto central, mas também quando comparados aos cerrados marginais nordestinos. Coccoloba latifolia e Maytenus erythroxyla, por exemplo, foram registradas tanto neste trabalho quanto em manchas de vegetação savânica na região costeira do estado da Paraíba (Oliveira-Filho \& Carvalho 1993), embora não em outras áreas de Cerrado do Brasil (Ratter et al. 2003).

Dentre as herbáceas, se destaca a espécie Trachypogon spicatus, gramínea cespitosa muito abundante no fragmento estudado e que está presente em outras áreas de Cerrado do Ceará (Costa et al. 2004) e do Brasil (Renvoize 1984; Tannus \&
Assis 2004). Além de T. spicatus, Andropogon bicornis e Andropogon selloanus (Poaceae), Chamaecrista flexuosa, Stylosanthes guianensis var. gracilis (=Stylosanthes gracilis Kunth) e Aeschynomene marginata (Fabaceae) também ocorrem tanto na área estudada quanto em outras áreas de Cerrado (Renvoize 1984; Lewis 1987; Tannus \& Assis 2004).

Entretanto, várias leguminosas herbáceas presentes na área estudada (e.g. Chamaecrista hispidula; Centrosema brasilianum; Stylosanthes angustifolia, Stylosanthes guianensis var gracilis, Clitoria laurifolia) são típicas de terrenos arenosos e são encontradas em áreas costeiras do Nordeste e não propriamente apenas no Cerrado (Lewis 1987). Assim como ocorre para a flora lenhosa, a flora herbácea se constitui em uma mistura de espécies de Cerrado com espécies da região costeira do Nordeste, o que reforça a idéia de Castro \& Martins (Castro 1994; Castro \& Martins 1999) de que os cerrados pré-litorâneos se constituem em um subgrupo florístico particular de Cerrado.

A riqueza de espécies na comunidade lenhosa (35 espécies nativas) ficou entre as mais baixas, em relação a outras áreas de cerrado sensu stricto compiladas por Costa \& Araújo (2007). Enquanto levantamentos fitossociológicos realizados na área núcleo do Cerrado, no estado de Goiás, mostraram que a riqueza de espécies variou de 81 a 92 espécies (Felfili et al. 2007), cerrados disjuntos da Amazônia, no extremo norte de distribuição do bioma, raramente excedem uma dúzia de espécies lenhosas na comunidade (Ratter et al. 2003). As áreas savânicas dos tabuleiros pré-litorâneos nordestinos parecem ficar em uma posição intermediária de riqueza de espécies por hectare, entre os cerrados amazônicos, geralmente pobres, e os centrais, geralmente muito ricos em espécies, o que poderá ser confirmado quando mais áreas desses cerrados pré-litorâneos forem inventariadas e comparadas.

Quanto às espécies exóticas na área estudada, é notável que Megathyrsus maximus (=Panicum maximum Jacq.) e Hyparrhenia rufa, duas das espécies de gramíneas invasoras mais comuns em Cerrados do Brasil (Pivello et al. 1999a,b; Tannus \& Assis 2004; Pivello 2005; Durigan et al. 2007) também estejam presentes no fragmento. Essas duas exóticas dominaram o estrato herbáceo em alguns trechos da vegetação, especialmente mais próximo às bordas. Já as exóticas lenhosas Ricinus communis e Calotropis procera, invasoras 

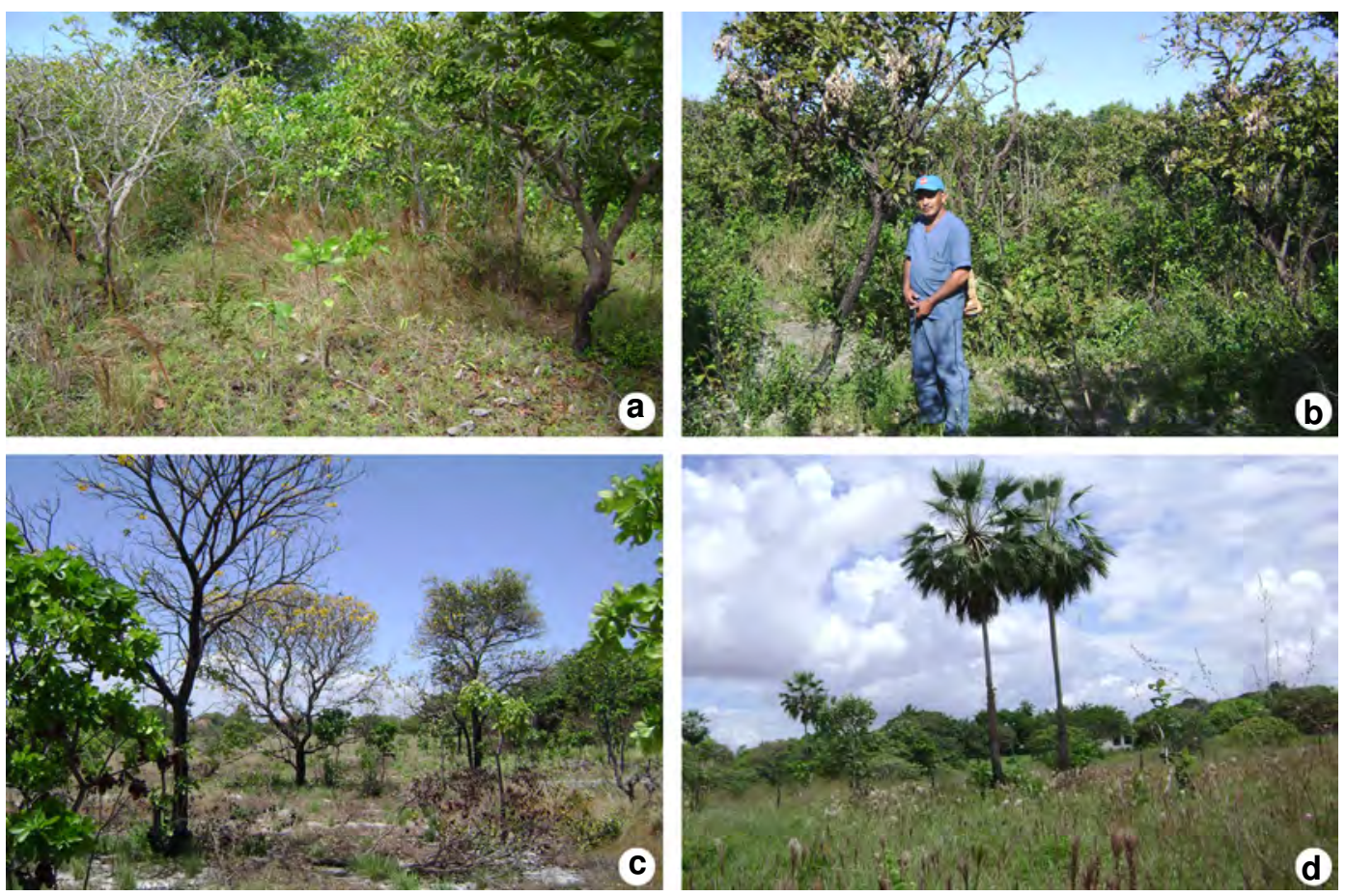

Figura 3 - a-d. Fisionomia do fragmento de vegetação estudado - a-c. áreas com fisionomia savânica; d. área alagável/paludosa ao sul do terreno (ver Fig. 1), com presença de Copernicia prunifera (palmeiras ao centro) e Andropogon bicornis (no estrato herbáceo). (Fotos: M. F. Moro)

Figure 3 - a-d. Physiognomy of the vegetation fragment studied - a-c. areas showing the savannic physiognomy; d. swampy site located in the south of the fragment (see Fig. 1). Note the presence of Copernicia prunifera (palms on center) and Andropogon bicornis (grass in the herbaceous layer). (Photos: M. F. Moro)

bastante comuns no Nordeste brasileiro, só foram observadas em associação com áreas degradadas do fragmento, como locais de depósito de lixo. Estas espécies, embora se enquadrem na definição de invasora de Richardson et al. (2000), não parecem ser competidoras agressivas em relação às espécies nativas e só foram registradas nos locais mais descaracterizados da área estudada.

Poucos exemplares de Albizia lebbeck foram registrados e isso deve ser indicativo que a espécie não é uma invasora agressiva no fragmento estudado (embora seja mais abundante em outros fragmentos de vegetação de Fortaleza). Quanto a Mangifera indica, indivíduos jovens foram observados apenas próximos de plantas adultas e assim, na área estudada, esta espécie não se comporta como invasora, mas apenas como exótica naturalizada ou mesmo exótica casual (sensu Richardson et al. 2000). Syzygium cumini é, dentre as espécies lenhosas, a invasora mais disseminada, já que adultos e plântulas foram encontrados em vários pontos da vegetação, embora com baixa abundância.
Em relação às exóticas lenhosas, Syzygium cumini parece ter se tornado invasora no fragmento a partir de seu uso pretérito como árvore frutífera no local. Albizia lebbeck deve ter se estabelecido na área a partir de seu uso na arborização das ruas do entorno, com dispersão de sementes para dentro do fragmento de vegetação. Ambas as exóticas, contudo, possuem baixa densidade no local estudado. Já Ricinus communis e Calotropis procera são invasoras de ampla dispersão no Nordeste brasileiro, ocupando conspicuamente locais degradados como beiras de estradas, terrenos baldios e outras áreas antropizadas.

\section{Estrutura fitossociológica}

Comparando-se o fragmento de vegetação estudado com 23 áreas de Cerrado citadas por Costa \& Araújo (2007), verificou-se que o número de espécies, a densidade e a área basal da comunidade lenhosa são baixas, mas estão dentro das amplitudes registradas para o Cerrado. A densidade e a área basal em diferentes comunidades de Cerrado é bastante variada, 

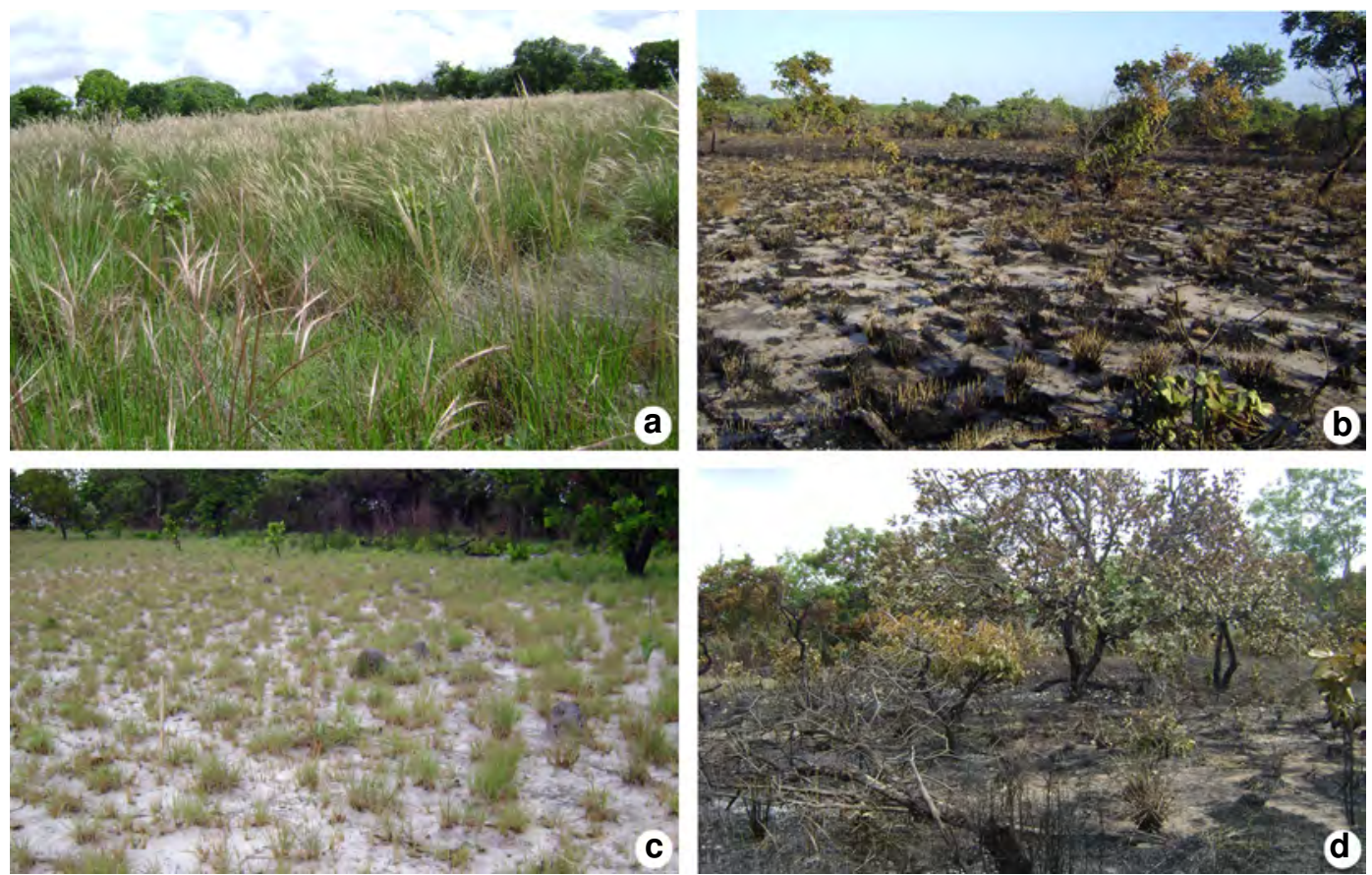

Figura 4 -a-d. Fisionomia do fragmento de vegetação estudado - a. trecho com fisionomia aberta ao norte do fragmento, com predomínio da gramínea Trachypogon spicatus no estrato herbáceo. Neste local, indivíduos juvenis de lenhosas como Himatanthus drasticus e Tabebuia aurea crescem entre as moitas da gramínea, mas são periodicamente mortos pelos incêndios; b-d-efeito do fogo sobre a vegetação; b. aproximadamente a mesma área da foto "e" após um incêndio em 4/8/2008; c. recuperação das moitas de T. spicatus três meses após o fogo; d. outro trecho da vegetação logo após o mesmo incêndio. (Fotos: M. F. Moro) Figure 4-a-d. Physiognomy of the vegetation fragment studied - a. site with open physiognomy in the north side of the fragment. The conspicuous species in the herbaceous layer is Trachypogon spicatus. Juveniles of woody species (e.g. Himatanthus drasticus and Tabebuia aurea) grow in this area, but are regularly killed by the frequent fires; $b$-d. effect of fire on the vegetation - b. approximately the same area of photo "e" after a fire in 4/8/2008; c. Recovery of $T$. spicatus three months after the fire; d. another site of the fragment after the same fire. (Photos: M. F. Moro)

desde 664 até 8.135 indivíduos por hectare e áreas basais desde $4,73 \mathrm{~m}^{2} /$ ha até $42,19 \mathrm{~m}^{2} /$ ha (Costa \& Araújo 2007). Isso se deve à grande variação fisionômica do cerrado sensu lato, desde ambientes florestais (cerradão) até campestres (campo limpo) (Gottsberger \& Silberbauer-Gottsberger 2006; Ribeiro \& Walter 2008). As fisionomias intermediárias (savânicas) são aquelas designadas como cerrado sensu stricto (Ribeiro \& Walter 2008) e a densidade e área basal da comunidade estudada se enquadram naquela registrada para outras áreas de cerrado sensu stricto (e.g. Felfili et al. 2002; Fidelis \& Godoy 2003) ou campo cerrado do Brasil.

Além da fisionomia savânica, a comunidade lenhosa estudada também é dominada por espécies da área núcleo do Cerrado, o que reforça a semelhança dos cerrados pré-litorâneos com outros cerrados do Brasil. Na área estudada, as espécies com maior IVI (e.g. Himatanthus drasticus, Stryphnodendron coriaceum, Annona coriacea,
Anacardium occidentale, Byrsonima crassifolia, Tabebuia aurea, Agonandra brasiliensis, Tapirira guianensis - ver tabela 2) são espécies frequentes em cerrados do Brasil central (Castro et al. 1999; Ratter et al. 2003; Mendonça et al. 2007), embora haja na comunidade a adição de espécies comumente encontradas na zona costeira nordestina (e.g. Mouriri cearensis, Tocoyena sellowiana, Coccoloba latifolia), mas que não se estendem às áreas núcleo do cerrado.

$\mathrm{O}$ fragmento de vegetação estudado possui fisionomia aberta e porte baixo, com $64 \%$ dos indivíduos lenhosos abaixo de $3 \mathrm{~m} \mathrm{e} 64 \%$ deles com diâmetros menores do que $6 \mathrm{~cm}$ (Figs. 2-5). No cerrado da Chapada do Araripe, onde a vegetação é mais densa, a densidade de indivíduos e a área basal ocupada pela comunidade vegetal foi de $2.224 \mathrm{ind} / \mathrm{ha}$ e $19,2 \mathrm{~m}^{2} / \mathrm{ha}$, respectivamente (Costa \& Araújo 2007), o que corresponde a uma densidade 1,8 vezes maior e área basal 2,6 vezes maior do que neste estudo. 
Essa situação é esperada, uma vez que, segundo moradores do entorno do terreno onde o fragmento de vegetação se localiza, incêndios têm atingido a área a cada um ou dois anos. Em áreas de Cerrado, as queimadas têm a capacidade de matar as partes aéreas de alguns indivíduos lenhosos, o que reduz a densidade da comunidade (Libano \& Felfili 2006; Medeiros \& Miranda 2008). Esse efeito pôde ser observado na área estudada após alguns incêndios ocorridos durante 2008, quando as partes aéreas de várias plantas foram eliminadas pela passagem do fogo (Fig. 4 b-d). Nesta situação, as plantas estão continuamente recuperando biomassa depois de cada queimada e podem reduzir sua eficiência de reprodução, além de que plântulas que potencialmente virariam árvores adultas são mortas (Miranda \& Sato 2005; Medeiros \& Miranda 2008). Os incêndios recorrentes aparentemente justificam a dominância de Himatanthus drasticus na comunidade, uma vez que na área estudada foi possível observar que esta espécie possui eficiente capacidade de rebrotar a partir das raízes, após a morte das suas partes aéreas pelo fogo.

\section{Potencial da área para conservação biológica}

A área estudada, por ser um fragmento de vegetação nativa que abriga diversas espécies vegetais, além de espécies da fauna (não tratadas nesse trabalho), é uma interessante oportunidade para a conservação no município de Fortaleza. Apesar do tamanho pequeno, o local abriga diversas espécies botânicas, além de alguns mamíferos (e.g. Callithrixjacchus (Linnaeus, 1758), Cavia sp.), aves (e.g. a área é sítio de nidificação/alimentação de Vanellus chilensis (Molina, 1782), Crotophaga ani Linnaeus 1758, Guira guira (Gmelin, 1788), entre outras espécies) e répteis (e.g. Iguana iguana (Linnaeus, 1758), Cnemidophorus ocellifer (Spix, 1825), Philodryas nattereri Steindachner, 1870).

Por abrigar uma mancha de vegetação savânica, também oferece oportunidade de conservar uma amostra dessa vegetação na paisagem já quase completamente urbanizada do Município. Criar uma Unidade de Conservação (UC) no local é, portanto, uma forma de buscar a manutenção das espécies nativas ainda presentes e, eventualmente, utilizar o local para projetos de educação ambiental e pesquisas acadêmicas. A lei 9.985/2000, que institui o Sistema Nacional de Unidades de Conservação da Natureza, estabelece 12 categorias de UCs oficialmente reconhecidas no Brasil, as quais são divididas em UCs de Proteção Integral e UCs de Uso Sustentável.

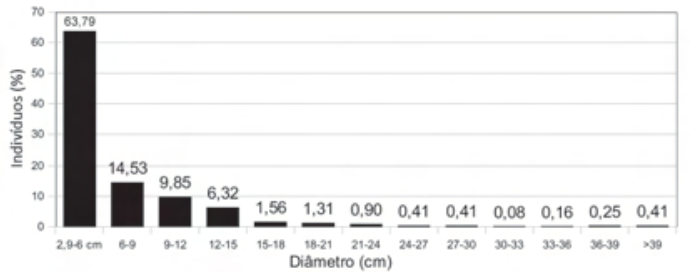

Figura 5 - Classes de diâmetro dos indivíduos lenhosos em 1 ha no fragmento de vegetação savânica estudado. Fortaleza, Ceará, 2008.

Figure 5 -Diameter classes of the woody plants sampled in 1 ha of the savannic vegetation fragment studied. Fortaleza, Ceará state, 2008.

Ambas as categorias podem ser estabelecidas por iniciativa do Poder Público Federal, Estadual ou Municipal. Dentre as categorias de UC disponíveis, a criação de uma Área de Relevante Interesse Ecológico municipal (ARIE), que é uma UC de uso sustentável, parece ser a mais apropriada para a proteção do fragmento de vegetação estudado. Segundo o Artigo 16 da lei 9.985/2000: "A Área de Relevante Interesse Ecológico é uma área em geral de pequena extensão, com pouca ou nenhuma ocupação humana, com características naturais extraordinárias ou que abriga exemplares raros da biota regional, e tem como objetivo manter os ecossistemas naturais de importância regional ou local e regular o uso admissível dessas áreas, de modo a compatibilizá-lo com os objetivos de conservação da natureza."

Considerando que o fragmento de vegetação estudado se constitui em uma mancha de pequena extensão de vegetação savânica costeira, e que diversas espécies da flora e fauna (incluindo pequenos mamíferos terrestres, répteis e anfíbios, os quais dependem da manutenção da área para sua sobrevivência) subsistem no local, em um município praticamente destituído da cobertura vegetal original, o enquadramento do fragmento como ARIE municipal se justifica. Isso estaria de acordo com o Plano Diretor de Fortaleza (Município de Fortaleza 2009), o qual estabelece em seu Artigo 142 a área estudada como "Zona Especial Ambiental" e que, em seu Artigo 14 (grifo nosso), ressalta a importância de se criar uma UC segundo o SNUC no local para garantir proteção duradoura à vegetação:

“Art. 14. São ações estratégicas para o uso, preservação e conservação da biodiversidade:

I - criar unidades de proteção integral e de uso sustentável nas áreas de abrangência dos sistemas ambientais frágeis, mediamente frágeis e de significativa 
relevância ambiental, compatibilizando-as com a Lei Federal n. 9.985, de 18 de julho de 2000, que institui o Sistema Nacional de Unidades de Conservação (SNUC);

\section{[...]}

VII - criar unidades de conservação no remanescente de cerrado (bairro Cidade dos Funcionários $^{1}$ ), na mata da Praia Mansa (Cais do Porto) e nas dunas móveis da Praia do Futuro;"

$\mathrm{O}$ fragmento estudado se constitui em uma mancha savânica costeira sobre os tabuleiros prélitorâneos da região Nordeste do Brasil, ainda pouco estudada e conhecida. Sua flora é composta por uma mistura de espécies que ocorrem em cerrados do Brasil central com espécies que não ocorrem nas áreas núcleo do domínio do Cerrado, mas que são comuns na região costeira nordestina. As espécies típicas de Cerrado, contudo, foram as que apresentaram os maiores IVI no fragmento analisado, ressaltando os vínculos estruturais e florísticos das savanas costeiras com outros Cerrados do Brasil.

A presença de espécies invasoras chama a atenção para a necessidade de controle de espécies não nativas no local. Entretanto, o maior perigo para a vegetação da área estudada é sua eliminação para expansão urbana. Neste sentido, o estabelecimento de uma UC municipal, seguida pela implementação de um plano de manejo e um programa de controle de exóticas, seria a maneira mais eficiente para garantir a conservação desta fitofisionomia peculiar e sua respectiva diversidade biológica.

\section{Agradecimentos}

Os autores agradecem à Coordenação de Aperfeiçoamento de Pessoal de Nível Superior (CAPES) a bolsa de mestrado concedida ao primeiro autor durante a realização desta pesquisa; à Empresa Brasileira de Correios e Telégrafos (Correios), por possibilitar o acesso á área de sua propriedade e pelo apoio logístico na realização dos trabalhos de campo; aos pesquisadores L.W. Lima Verde (Orchidaceae), A. Fernandes (Leguminosae), E.P. Nunes (Leguminosae), E.B. Souza (Rubiaceae), R.C. Oliveira (Poaceae), I.R. Costa (Myrtaceae) e M.I.B. Loiola (Erythroxylaceae) o auxílio nas identificações. Agradecemos a M.O. Teles de Menezes e a F.W. Amorim as valiosas sugestões para a melhoria do texto e auxílio para a montagem da prancha de fotos.

'O remanescente referido pela lei se localiza, na verdade, no bairro Cambeba, adjacente ao bairro Cidade dos Funcionários.

\section{Referências}

APG II - Angiosperm Phylogeny Group. 2003. An update of the Angiosperm Phylogeny Group classification for the orders and families of flowering plants: APG II. Botanical Journal of the Linnean Society 141: 399-436.

Breuste J.H. 2004. Decision making, planning and design for the conservation of indigenous vegetation within urban development. Landscape and Urban Planning 68: 439-452.

Bridson, D. \& Forman, L. 1998. The herbarium handbook. Royal Botanical Gardens, Kew, Londres. 334p.

Brower, J.; Zar, J. \& Von Ende, C.N. 1997. Field and laboratory methods for general ecology. McGrawHill Science. 288p.

Castro, A.A.J.F. 1994. Comparação florístico-geográfica (Brasil) e fitossociológica (Piauí - São Paulo) de amostras de cerrado. Tese de Doutorado. Universidade Estadual de Campinas, Campinas. 520p.

Castro, A.A.J.F. \& Martins, F.R. 1999. Cerrados do Brasil e do Nordeste: caracterização, área de ocupação, considerações sobre sua fitodiversidade. Pesquisa em Foco 7: 147-178.

Castro, A.A.J.F.; Martins, F.R.; Tamashiro, J.Y. \& Shepherd, G.J. 1999. How rich is the flora of Brazilian Cerrados? Annals of the Missouri Botanical Garden 86: 192-224.

Costa, I.R.; Araújo, F.S. \& Lima-Verde, L.W. 2004. Flora e aspectos auto-ecológicos de um encrave de cerrado na chapada do Araripe, Nordeste do Brasil. Acta Botanica Brasilica 18: 759-770.

Costa, I.R. \& Araújo, F.S. 2007. Organização comunitária de um encrave de cerrado sensu stricto no bioma caatinga, chapada do Araripe, Brabalha, Ceará. Acta Botanica Brasilica 21: 281-291.

Durigan, G. 2003. Métodos para análise de vegetação arbórea. In: Cullen Júnior, L.; Rudran, R. \& Valladares-Padua, C. (eds.). Métodos de estudos em biologia da conservação e manejo da vida silvestre. Universidade Federal do Paraná/Fundação O Boticário de Proteção à Natureza, Curitiba. 667p.

Durigan, G.; Siqueira, M.F \& Franco, G..A.D.C. 2007. Threats to the cerrado remnants of the state of São Paulo, Brazil. Scientia Agricola 64: 355-363.

Eiten, G. 1972. The cerrado vegetation of Brazil. Botanical Review 38: 201-341.

Eiten, G.1978. Delimitation of the cerrado concept. Vegetatio 36: 169-178.

Felfili, J.M.; Nogueira, P.E.; Silva Júnior, M.C.; Marimon, B.S. \& Delitti, W.B.C. 2002. Composição florística e fitossociologia do cerrado sentido restrito no município de Água Boa - MT. Acta Botanica Brasilica 16: 103-112.

Felfili, J.M.; Rezende, A.V. \& Silva Júnior, M.C. 2007. Biogeografia do bioma cerrado: vegetação e solos da 
Chapada dos Veadeiros. Universidade de Brasília, Brasília. 256p.

Fernandes, A.1990. Temas fitogeográficos. Stylus Comunicações, Fortaleza. 116p.

Fidelis, A.T. \& Godoy, S.A.P. 2003. Estrutura de um cerrado stricto sensu na gleba cerrado pé-de-gigante, Santa Rita do Passa Quatro, SP. Acta Botanica Brasilica 17: 531-539.

Figueiredo, M.A. \& Fernandes, A. 1987. Encraves de cerrado no interior do Ceará. Ciência Agronômica 18: 103-106.

Figueiredo, M.A.1997. A cobertura vegetal do Ceará (Unidades Fitoecológicas). In: Atlas do Ceará. Governo do Estado do Ceará/IPLANCE, Fortaleza.

Fortaleza. 2003. Inventário ambiental de Fortaleza. Prefeitura Municipal de Fortaleza, Fortaleza.

Gottsberger, G. \& Silberbauer-Gottsberger, I. 2006. Life in the cerrado: a South American Tropical Seasonal Vegetation. Vol I. Reta Verlag, Ulm. 277p.

IBGE - Instituto Brasileiro de Geografia e Estatística. 2000. Censo Demográfico Brasileiro - ano de 2000.

IPECE - Instituto de Pesquisa e Estratégia Econômica do Ceará. 2008 [online]. Perfil básico municipal: Fortaleza. Disponível em <http://www.ipece.ce.gov.br/ publicacoes/perfil_basico/perfil-basico-municipal2008>. Acesso em 17 set 2009.

Lewis, G.P. 1987. Legumes of Bahia. Royal Botanic Gardens, Kew. 369p.

Libano, A.M. \& Felfili, J.M. 2006. Mudanças temporais na composição florística e na diversidade de um cerrado sensu stricto do Brasil Central em um período de 18 anos (1985-2003). Acta Botanica Brasilica 20: 927-936.

McCune, B. \& Grace, J.B. 2002. Analysis of ecological communities. MJM, Gleneden Beach. 300p.

McKinney, M.L. 2002. Urbanization, biodiversity, and conservation. BioScience 52: 883-890.

McKinney, M.L. 2006. Urbanization as a major cause of biotic homogenization. Biological Conservation 127: 247-260.

Medeiros, M.B. \& Miranda, H.S. 2008. Post-fire resprouting and mortality in cerrado woody plant species over a three-year period. Edinburgh Journal of Botany 65: 53-68.

Mendonça, R.C.; Filgueiras, T.S. \& Fagg, C.W. 2007. Análise florística da Chapada dos Veadeiros. In: Felfili, J.M.; Rezende, A.V. \& Silva Júnior, M.C. (eds.). Biogeografia do bioma cerrado: vegetação e solos da Chapada dos Veadeiros. Universidade de Brasília, Brasília. 256p.

Miranda, H.S. \& Sato, M.N. 2005. Efeitos do fogo na vegetação lenhosa do Cerrado. In: Scariot, A.; SousaSilva, J.C. \& Felfili, J.M. (eds.). 2005. Cerrado: ecologia, biodiversidade e conservação. Ministério do Meio Ambiente, Brasília. 439p.

Mori, S.A.; Silva, L.A.M.; Lisboa, G. \& Coradin, L. 1985. Manual de manejo do herbário fanerogâmico. Centro de Pesquisas do Cacau, Ilhéus. 97p.

Município de Fortaleza. Lei Complementar n. ${ }^{\circ}$ 062, de 02 de fevereiro de 2009. Institui o Plano Diretor Participativo do Município de Fortaleza e dá outras providências. Diário Oficial do Município, Fortaleza, CE, Ano LVI, n. ${ }^{\circ}$ 14.020. 13 de março de 2009.

Oliveira-Filho, A.T. \& Carvalho, D.A. 1993. Florística e fisionomia da vegetação no extremo norte do litoral da Paraíba. Revista Brasileira de Botânica 16: 115-130.

Pivello, V.R.; Shida, C.N. \& Meirelles, S.T. 1999a. Alien grasses in Brazilian savannas: a threat to the biodiversity. Biodiversity and Conservation 8: 1281-1294.

Pivello, V.R.; Carvalho, V.M.C.; Lopes, P.F.; Peccinini, A.A. \& Rosso, S. 1999b. Abundance and distribution of native and alien grasses in a "cerrado" (Brazilian savanna) Biological Reserve. Biotropica 31: 71-82.

Pivello, V.R. 2005. Manejo de fragmentos de Cerrado: princípios para a conservação da biodiversidade. In: A. Scariot; J.C. Sousa-Silva; J.M. Felfili (eds.). 2005. Cerrado: ecologia, biodiversidade e conservação. Ministério do Meio Ambiente, Brasília. 439p.

Ratter, J.A.; Bridgewater, S. \& Ribeiro, J.F. 2003. Analysis of the floristic composition of the brazilian cerrado vegetation III: comparison of the woody vegetation of 376 areas. Edinburgh Journal of Botany 60: 57-109.

Renvoize, S.A. 1984. The grasses of Bahia. Royal Botanic Gardens, Kew. 301p.

Ribeiro, J.F. \& Walter, B.M.T. 2008. As principais fitofisionomias do bioma cerrado. In: Sano, S.M.; Almeida, S.P. \& Ribeiro, J.F. (eds.). Cerrado: ecologia e flora. Vol. I. Embrapa, Brasília. 406p.

Richardson, D.M.; Pysek, P.; Rejmánek, M.; Barbour, M.G.; Panetta, F.D. \& West, C.J. 2000. Naturalization and invasion of alien plants: concepts and definitions. Diversity and Distributions 6: 93-107.

Tannus, J.L.S. \& Assis, M.A. 2004. Composição de espécies vasculares de campo sujo e campo úmido em área de cerrado, Itirapina - SP, Brasil. Revista Brasileira de Botânica 27: 489-506.

UNDP, UNEP, WB, WRI - United Nations Development Programme, United Nations Environment Programme, World Bank, World Resources Institute. 2000. World resources 2000-2001: people and ecosystems: the fraying web of life. Elsevier, Amsterdam. 389p.

Whittaker, R.H. 1975. Communities and ecosystems. MacMillan, Nova York. 385p. 